\title{
SONHO E EDUCAÇÃO: DESLOCAMENTOS PELA FILOSOFIA DA DIFERENÇA
}

\author{
DREAM AND EDUCATION: DISPLACEMENTS BY THE PHILOSOPHY OF DIFFERENCE \\ SUEÑO Y EDUCACIÓN: DESPLAZAMIENTOS A TRAVÉS DE LA FILOSOFÍA DE LA DIFERENCIA
}

\author{
CORAZZA, Sandra Mara ${ }^{1}$ \\ REIS, Marina dos²
}

\section{RESUMO}

Este artigo trata a atualidade da função social e poética do sonho via a Filosofia da Diferença e Educação. Entende o potencial artístico e filosófico dos atravessamentos possíveis a cada abordagem do sonho (biográfica, transpessoal ou simbólica) no pensamento que traduz o arquivo da educação pelo onírico. Pensa a invenção pelos deslocamentos que o sonho provoca nos corpos, abrindo espaços aos revezamentos entre o individual e o social, entre a escrita e a educação.

Palavras-chave: Sonho. Educação. Filosofia da Diferença.

\section{ABSTRACT}

This article deals with the actuality of the social and poetic function of the dream via the Philosophy of Difference and Education. It understands the artistic and philosophical potential of the possible crosses to each approach of the dream (biographical, transpersonal or symbolic) in the thought that translates the archive of education by the work-dream-like. It thinks the invention by the displacements that the dream causes in the bodies, opening spaces to the shifts between the individual and the social, between writing and education.

Keywords: Dream. Edication. Philosophy of Difference.

\section{RESUMEN}

Este artículo trata la actualidad de la función social y poética del sueño vía la Filosofía de la Diferencia y Educación. Entiende el potencial artístico y filosófico de los posibles cruces a cada enfoque del sueño (biográfico, transpersonal, simbólica) en el pensamiento que traduce el archivo de la educación por lo onírico. Piensa la invención por los desplazamientos que el sueño provoca en los cuerpos, abriendo espacios a los intercambios entre lo individual y lo social, entre la escritura y la educación.

Palabras clave: Sueño. Educación. Filosofía de la Diferencia.

\footnotetext{
${ }^{1}$ Universidade Federal do Rio Grande do Sul, Porto Alegre/RS, Brasil.

${ }^{2}$ Universidade Federal do Rio Grande do Sul, Porto Alegre/RS, Brasil.
} 


\title{
SONHO E EXISTÊNCIA
}

A potência espiritual do sonho pode ser verificada pelas impressões do sonhador, em especial a aparência de que existe, materialmente, um outro mundo com outras criaturas. Há uma sensação de certeza de que isso foi vivido: por quem? para quem? quando? É uma conversa por vezes emudecida, ou noutra linguagem - línguas menores, tais como a língua do susto, não-dominante. Mesmo arquétipos anunciam ao sonhador aquilo que ele não sabia. Tal vivência gera-nos signos a-traduzir, os quais podemos tentar traduzir e interpretar, ou conviver com a sua incógnita, e com a estranha capacidade de repetição oniróide, evento que gera diferenças mínimas, algo não explicado completamente pela neurobiologia. Sondamos imagens do tipo não-imagens no sonho. Benjamin (2011) e Foucault (2012) trataram o sonho já como uma interpretação; Borges (1985) fabricou tigres, porque antes o seu medo em sonho desejou tigres ${ }^{3}$.

Nessa sensação que mescla sonho e imaginação, encontramos uma análise valorosa ao nosso estudo de sonho em educação no ensaio do filósofo Michel Foucault (1926-1984), intitulado Sonho, Imaginação e Existência, publicado em 1954 na introdução de Sonho e Existência, escrito do psiquiatra suíço Ludwig Binswanger (1881-1956) ${ }^{4}$, pioneiro na psicologia existencial. Os estudos do sonho pela Filosofia da Diferença pesquisam a poética da tradução docente pela imagem e por sua negação onírica, pois:

\begin{abstract}
A imagem não explica: convida-nos a recriá-la e, literalmente, a revivê-la. O dizer do poeta se encarna na comunhão poética. A imagem transmuta o homem e converte-o por sua vez em espaço onde os contrários se fundem. E o próprio homem, desgarrado desde o nascer, reconcilia-se consigo quando se faz imagem, quando se faz outro. (PAZ, 2015, p. 50)
\end{abstract}

Pensando deslocamentos possíveis à educação contemporênea pelo fluxo das forças em sonhografias da filosofia da diferença, desejamos o Sonhar da pesquisa-docência, a Aula como essa negação da aula-dada, um não-lugar, brecha aos revezamentos entre a escrita e o aprendizado via narrativas. Sem necessariamente seguir receitas psicanalíticas e da semiótica da linguagem, sonhar sem reproduzir a moral ${ }^{3}$ e o juízo soberanos, mas atentando a essa função social transindividual do onirismo com os quadros sociais, em seu processo de individuação e de valoração. O controle indireto, como tudo o que nos ocorre na vida vígil, reverbera no inconsciente. Toda a moral ${ }^{5}$ da civilização

\footnotetext{
${ }^{3}$ Sobre o caráter infinito e inacabado da interpretação, no ensaio que aborda o debate de Foucault ([1975],1997) acerca das técnicas de interpretação de Nietzsche, Freud e Marx, bem como sobre duas obras de Deleuze, Lógica do Sentido e Diferença e Repetição, ambas de 1969, temos que - além do postulado de que os símbolos, da semelhança no séculos XVI, desdobram-se em sua amplitude no século XIX - justamente por ser inacabada, a interpretação não possui nada a interpretar, "não há nada absolutamente primário a interpretar, porque no fundo já tudo é interpretação, mas a interpretação de outros símbolos" (FOUCAULT, 1997, p. 22).

${ }^{4}$ A referência à obra de Binswanger, título original Traum und Existenz, primeira publicação em 1930, utilizada pela tradução do ensaio de Foucault (2002) que utilizamos está no volume I da Coleção Ditos e Escritos. Consta à página 71: BINSWANGER (L.), Le Rêve et l'existence. Trad. J. Verdeaux, Paris: Desclée de Brouwer, 1954, p. 9-128. ${ }^{5}$ Moral (Moral) para Nietzsche, de acordo com Wotling (2011), são múltiplas interpretações, instrumentos de cultura ou de educação, e cada moral, em seu contexto, está "apoiada em um sistema preciso de valores", é um produto de uma realidade (falsa interpretação) afirmada a partir das interpretações dos corpos e de tudo o que os constitui (afetos, instintos). A moralidade é a "obediência aos costumes", o adestramento dos corpos pela tradição (WOTLING, 2011, p. 47 e 49). A questão impulsiva: quais os valores dos valores que constituem essa moral, pois geradora de novas pulsões nos corpos que estão sob sua realidade?
} 
incorporada em nossa cultura impõe, de certa forma (inclusive as cenas e os enredos dos sonhos e dos pensamentos na vigília) quadros socias sob determina égide, em geral moralista. A educação pelo sonho incorpora-se na dinâmica individual e coletiva desses quadros sociais, remodelando valores durante a sua elaboração. Atentamos a esses processos potentes de imaginação. É sonhando que nos surpreendemos não apenas com novas ideias, situações, respostas, mas também temos prazer de lembrar dessa sensação inédita e, por vezes, premonitória. Mesmo quando um sonho se repete, a sensação nunca é igual.

A educação em sonho e poesia pressupõe, portanto, modalidades da existência no mundo onírico. Essa existência em sonho é uma rede de significações, comprimida e de "evidência turva" (FOUCAULT, 2002, p. 74). A análise do sonho é movimento concreto de acesso às formas fundamentais da existência, e não apenas o ato de decifrar um símbolo hermenêutico (no sentido de fechado em si): "o sentido do sonho se desdobra de modo contínuo da cifra da aparência às modalidades da existência”. Nesse raciocínio crítico com Foucault, a psicanálise de Freud inverteu a experiência onírica (a sagrada e ancestral) de um "non-senses da consciência" — na qual o sonho desatava os sentidos esfumaçados da vida vígil (como nos povos primitivos) — para um "sentido do inconsciente", ao ter atribuído "muita importância à realização do inconsciente como instância psíquica e conteúdo latente" (FOUCAULT, 2002, p. 75). Assim, Freud negligenciou o "problema da significação e imagem", pois o sonho já é uma interpretação que trai o sentido enquanto o realiza. O termo dessa força contrária ao desejo é o contradesejo, que se consuma em imagem concreta na contradição do sonho. Por exemplo, a "chama onírica" do desejo sexual, sendo o fogo o desejo e a chama, o contradesejo:

O sonho é misto funcional; se a significação se investe de imagens, é por um excesso, como uma multiplicação de sentidos que se superpõem, e se contradizem. A plástica imaginária do sonho não é, para o sentido que nela emerge, senão a fórmula de sua contradição. (FOUCAULT, 2002, p. 76)

Nessa articulação acerca do sentido e da imagem do sonho, segundo o filósofo francês, a psicanálise deu ao sonho o estatuto de fala, e isso é um paradoxo, pois Freud não abordou justamente a estrutura morfológica (figuras) e sintática (regras) que formam o mundo a ser expresso pela fala, aquilo que dá corpo ao que ela quer dizer: "a imagem é um pouco mais que a realização do sentido", e suas camadas se dão não apenas por "proposições significativas" (FOUCAULT, 2002, p. 77). Ou seja, entendemos que o sonho é estrutura da própria experiência onírica, não somente habitada pela proposição de recalque (freudiano) do desejo. Pela psicanálise, o sentido do sonho se esconde pelo recalque nas formas expressivas da imagem, em vez de permanecer implícito ou de ser uma formulação verbal. E essa é a resposta de Freud sobre a imagem ser a manifestação do sentido do sonho, resposta que Foucault (2002, p. 78-79) apresenta-nos à sua pergunta de por que o sentido do sonho é uma imagem para Freud.

Defendemos que a imagem do sonho seja o ponto de partida investigativo, mas não apenas (como na psicanálise) aproximando imagem e significado, já que não há nada disfarçado ou escondido à vista do sonho (TIRKKONEN, 2018, p. 35). Na experiência onírica analisada pela arqueologia 
foucaultiana, tem-se o contraste da perspectiva pessoal (primeira pessoa) com a científica (terceira pessoa) - por exemplo, o trabalho do espírito para conceber um retângulo ou uma paisagem pode ser entendido da mesma maneira. Nessa concepção de movimento da imagem do sonho, a experiência de se tornar uma serpente é diferente da imagem de uma parte do corpo transformada em serpente ${ }^{6}$.

Ao sonhografar, a poética da escrita e do pensamento tradutório está imersa nesse imbricado conjunto de indícios, quando o docente depara-se com o arquivo da educação que deseja traduzir: suas partes a-traduzir saltam como signos que nos afetam, mesmo sem a tradução imediata de indícios, o corpo marcado passa a transcrevê-los em camadas de possíveis significações, e isso sonha Aulas.

Nessa semantização das imagens, criada pelo sujeito, onde nos interessa a invenção e o exercício de imaginação ativa, há a superfície de indícios. Tirkkonen (2018) elabora, a partir de Husserl, o conceito de significado-dado pelo próprio sujeito (tradução nossa de meaning-giving) ${ }^{7}$. Um exemplo evocado de Foucault (2002, p. 86) é: avistar buracos na neve para um caçador significa pistas de um movimento da caça e seu pensamento, portanto, trabalhará diferentemente de alguém que simplesmente avista uma paisagem de neve com vários buracos espalhados, podendo perguntar-se quem os fez?, quando?, como? Portanto a conexão entre o sinal (indícios e imagem gerada) e o significado existe, mas no sujeito. E tal significado não é arbitrário, mas composto de um horizonte significativo da tradução/construção/interpretação formulado pelo movimento intelectual da imaginação do sujeito. Tal declaração inverte o poder terapêutico, por exemplo, pois o detentor da significação de seu sonho (arrisca-se dizer, da chave do sonho) é o paciente e não o terapeuta.

O sonho é uma poética da sutilidade da alma, ideia desenvolvida em Baader, Novalis (17721801) e Carus (Titus Lucretius Carus: ca. 99 a.C. - ca. 55 a.C.) citados por Foucault (2002). Sonhar é uma espécie de intuição que clareia o próprio interior de quem sonha, como uma "visão objetiva", para "além das mediações dos sentidos" (FOUCAULT, 2002, p. 95-96). Por essa perspectiva, nossa interpretação sonhográfica age no antagonismo entre a sensibilidade interna e externa do sonhador e, no núcleo do sonho, no sono profundo, teríamos o desabrochar do mundo subjetivo de "pesadas significações", em oposição ao movimento que "se adianta ao mundo". No sonho, "todo o universo se consome por uma imagem instantânea". Tal relação do sonho com o mundo é, portanto, imaginária, e uma concepção de alguma verdade do mundo antecipada pela imagem se reconstitui diante do sonhador, a uma distância e de forma turva, como "imersão do espírito na noite inconsciente" (FOUCAULT, 2002, p. 95-96). O sonho, para o filósofo Carus, deixa-se habitar pela objetividade do espírito que sonha e livremente se entrelaça ao universal; enquanto que na vigília os sentidos apenas nos apresentam em "oposição ao mundo" (FOUCAULT, 2002, p. 96). Aderente à essa noção da cosmogonia no sonho, a poética por essa via imaginativa é restaurada na evocação da escrita sonhográfica, temos a "imagem primeira da poesia, e a poesia, a forma primitiva da linguagem" (FOUCAULT, 2002, p. 100).

\footnotetext{
${ }^{6}$ Exemplo citado por Tirkkonen (2018, p. 36), a partir do ensaio Fenomenologia da percepção, de Merleau-Ponty (1908-1961).

${ }^{7}$ Segundo Tirkkonen (2018, p. 36), Foucault (1954) baseou-se em algumas premissas husserlianas para repensar o conteúdo do sonho e a significação.
} 


\section{A ATUALIDADE DA ONIROCRÍTICA}

Em uma realidade em desrazão, o que nos diriam nossos sonhos? Foucault (2012) apresentou na conferência de 1983 uma análise crítica e filosófica da Onirocrítica do pensador grego Artemidoro de Daldis, escrita no século II. A obra foi um método, um manual e também um tratado. A literatura sobre esse tema foi abundante na época, embora só tenha restado a onirocrítica na íntegra. A análise dos sonhos fazia parte das técnicas de existência, neles os deuses ordenavam, advertiam, anunciavam presságios e aconselhavam atitudes. Os sonhos eram espécie de oráculos em alerta. Assim, talqualmente na técnica divinatória, dos xamãs, dos sacrificadores, deveria também o oniromante estar atento aos sinais orgânicos das partes do sonho. Essa técnica leva-nos a uma aproximação da escrita de sonhos, pela tradução e interpretação imaginativa, numa subjetividade crítica que perspectiva sobre as recolhas da vida vígil outras possibilidades, inclusive as de fabulação e invenção. Assim, a pergunta de Foucaul (2012) segue atual: "Como fazer para decompor um sonho em elementos e levar em conta esse todo na decifração de cada elemento?" (FOUCAULT, 2012, p. 160). Como prática de si, o livro de Artemidoro está a serviço dos atentos aos sonhos, para uma "reflexão salutar — therapeia sôteriadês" (FOUCAULT, 2012, p. 160).

$\mathrm{Na}$ Onirocrítica são distintas algumas formas de visões noturnas básicas para uma interpretação a nossos enredos (adaptado de FOUCAULT, 2012, p. 163-164): a Enupnia (en-hupnion) são sonhos do desejo individual e representam os afetos atuais do sujeito, estabelecem-se na atualidade; manifestam o próprio estado presente do sonhador, isto é, a falta ou excesso, no corpo; o medo ou o desejo, na alma. Os Oreinein (to on éirei) são sonhos de acontecimentos do mundo, sonhos do ser. Dizem o que já está encadeado para um futuro próximo. Modificam e excitam (oreinel) a alma. Em ambos os tipos de sonhos há ainda a distinção quanto à mensagem: os teoremáticos, se diretamente inteligíveis, transparentes; e os alegóricos, cuja interpretação é necessária para decifrar analogias, relações indiretas, aproximações.

Uma constatação de Foucault (2012) na sociedade de Artemidoro, mas que permeia nossos dilemas atuais, diz respeito ao quanto os discursos interpõem costumes a uma realidade jamais esperada, modelizam vontades e "almas" a valores moralizantes e ressentidos. Acerca do sujeito que sonha, Foucault averigua certo moralismo em Artemidoro, pois as almas ditas virtuosas, as quais dominam os movimentos irracionais, sonharão virtudes. Seus sonhos de acontecimentos serão do tipo teoremáticos porque, segundo Artemidoro, os deuses falam diretamente às almas puras. Ainda, nos sonhos de estado, quanto mais elaborada a alma, tanto mais indireto será o sonho. Um leigo em onirocrítica sonhará, portanto, prontamente com o que deseja. Poderíamos problematizar e perguntar: Será?

Essa constatação obviamente foi explanada e diluída como na compensação onírica analisada por Jung (1954), ou nos sonhos traumáticos por Freud (1966). Mas essa acepção moral, embora pareça um registro histórico, abarca discursos sociais, num retrocesso à dicotomia do bem e do mal, por exemplo. O estudo dos sonhos mostra-nos um importante acesso a nossas transformações subjetivas nessa existência que é deveniente e não estanque. Antecipa-nos pistas da consciência vígil 
e dos fragmentos inconscientes aparentemente inofensivos, também de nossa subjetividade. Os sonhos teoremáticos, diferentemente dos alegóricos, não dão espaço temporal a interpretações, ocorrendo prontamente à sua manifestação. Considerando os modos de ser do sujeito, tipos de sonho, métodos, temos que as almas virtuosas nunca sonham sonhos de estado e frequentemente sonham sonhos de acontecimentos teoremáticos; as almas comuns, se experientes, sonham sonhos de estados diretos e com frequência os de acontecimentos teoremáticos; as almas comuns e inexperientes terão com frequência sonhos de estados diretos e os de acontecimentos alegóricos (FOUCAULT, 2012, p. 166-167).

No deciframento da alegoria, é possível desmembrá-la por analogias e pela lei da semelhança, por diversos meios, na identidade qualitativa; na identidade das palavras; no parentesco simbólico; pelas crenças, pelos ditos populares e pelos mitos. Ainda, Artemidoro reconhece a ligação de natureza: "a figura sonhada e o real anunciado pertencem a mesma ordem das coisas". É na analogia de valor que Artemidoro analisa se os eventos que ocorrerão são favoráveis ou não, via sistema binário (bom ou mau, feliz, infeliz). "Um sonho tem prognóstico bom se o ato que ele representa é bom em si mesmo" (FOUCAULT, 2012, p. 168).

São seis os critérios de valores de Artemidoro, admitindo exceções, ou seja, inversões desses valores:

a) O ato representado está de acordo com a natureza?

b) Está de acordo com a lei?

c) Está de acordo com os costumes?

d) Está de acordo com a tekhnê — ou seja, com as regras e práticas que permitem a uma ação atingir seus objetivos?

e) Está de acordo com o tempo, isto é, realiza-se no momento e nas circunstâncias adequadas?

f) Possui um nome em si mesmo que é de bom augúrio?

As inversões devem ser assim interpretadas, portanto: certos sonhos são bons por fora e maus por dentro, outros, pelo contrário, maus por fora e bons por dentro. (FOUCAULT, 2012, p. 168)

As perguntas apresentadas por Foucault (2012), a partir das perguntas de Artemidoro sobre os valores morais nos sonhos são problematizações às nossas subjetividades e construções de perspectivas diante de nossa atualidade, já que um sonho é, antes de tudo, uma interpretação de partes retiradas de uma realidade.

Outra constatação interessante do ponto de vista da subjetividade nos quadros sociais está relacionada à interpretação dada por Artemidoro aos sonhos sexuais como revelação da ética do sujeito, e não como sonhos moralistas. Nos sonhos sexuais o sujeito é o autor do sonho, mas também é o protagonista. Nesses tipos, aplicam-se as duas grandes regras da onirocrítica: o sonho diz o ser na forma de analogia e diz o acontecimento, se a fortuna ou o infortúnio, se a felicidade ou infelicidade. Essas mensagens oníricas assim interpretadas caracterizam no real o modo de ser do sujeito e dizem isso através de uma relação de analogia com o modo de ser do "ator-sonhador" no sonho de enredo sexual. Foucault (2012) comenta também que três capítulos e mais anotações esparsas de Artemidoro 
foram dedicados aos sonhos sexuais, cujas divisões não são categorias rigorosamente fixas. Por exemplo, sobre os atos conforme a lei (kata nomon), são considerados sonhos dentro da lei os sonhos de adultério. Isso testemunha a sociedade dessa época, na qual ou a esposa, ou a amante/pellex, ou a prostituta, estavam categorizadas pelos homens juntamente com os escravos da casa, ou seja, esses corpos eram parte dos bens do proprietário ${ }^{8}$.

O autor das cenas dos sonhos sexuais é também o seu ator, assim, pela onirocrítica, tais sonhos "pressagiam o destino do sonhador na vida social; o ator que ele é na cena sexual antecipa o papel que será o seu na cena familiar, na do trabalho, dos negócios, da cidade" (FOUCAULT, 2012, p. 179). Então o sonho sexual é analisado como uma cena social, cujos personagens são tipos de perfis sociais. Além disso, o sonho sexual na interpretação de Artemidoro, é reduzido à prática sexual, sem nenhuma variação como carícias, fantasmagoria ou outras complicações. Representa o jogo social, da superioridade ou da inferioridade, do possuidor e possuído, da dominação e submissão, ou seja, o jogo de poder e jogo econômico (FOUCAULT, 2012, p. 180). A atribuição de valores nesses sonhos estabelece-se a partir da relação com o papel social do ator do sonho, portamto, simula a relação social vígil entre os parceiros, e é o sonhador o qualificador. Na seção da onirocrítica que versa sobre o significado das diferentes partes do corpo no sonho, Foucault (2012, p. 183) traz o exemplo do membro viril, para mostrar a comunicação entre o sujeito ativo na relação sexual e como isso lhe situa nas relações sociais. Anankaion (o órgão masculino) é "o elemento necessário, aquele cujas necessidades nos coagem e por força do qual coagimos os outros. É significante de todo um conjunto de relações e atividades que fixam o status do indivíduo na cidade e no mundo [...]" (FOUCAULT, 2012, p. 100).

A atualidade da análise de Foucault (2012) reside sobremaneira nessas interpretações as quais contrastam com as interpretações psicanalíticas, pois os sonhos sexuais contêm significação social, relações de gênero e de subjetividade.

\section{O SONHAR EM SEUS DESLOCAMENTOS SOCIAIS E POÉTICOS}

O estudo dos sonhos em sua função social torna-se uma prática poética de si e modelizadora de novas perspectivas de deslocamentos possíveis na cultura e educação, individual e coletivamente.

Outro deslocamento à educação contemporânea está na potência imagética e da sabedoria feminina pelos sonhos de mulheres, já que contrastam com a maioria dos estudos e significado dos sonhos em nossa cultura eminentemente temperada pelos referenciais masculinos, os quais mantiveram em subordinação as emoções e a própria condição da mulher por um percurso cultural e histórico considerável:

Embora as imagens masculinas interiores sejam com frequência guias inestimáveis para as mulheres [como o animus], ultimamente parece-me que nosso aspecto masculino interior tem sido demasiadamente enfatizado; muito tem-se escrito sobre ele; e ele tem sido visto com tanto preconceito cultural que se tornou difícil escrever sobre ele sem criar estereótipos [...] as próprias mulheres têm de começar a definir seu lado masculino em todas as suas formas construtivas e destrutivas conforme ele aparece em suas vidas e em seus sonhos. (SIGNELL, 1998, p. 26-27)

8 A palavra sôma, que designa o corpo, "se refere tanto às riquezas quanto aos bens" (FOUCAULT, 2012, p. 177). 
A sabedoria cultural e ancestral das mulheres, das deusas ctônicas, das heroínas, das irmãs, das bruxas, das mães, desse manancial feminino cujas narrativas ainda não estão marcando livros de história ou da literatura mundial, ressonam nos sonhos individuais ou coletivos de nossos corpos terrenos e terrosos. Ensinamentos de outras formas de ser e de pensar, formas de reger a vida que transpassam a dicotomia ocidental e por muitas vezes a hierárquica de relações de poderes e saberes. Ressalva-se que "feminino e/ou masculino" são expressões simbólicas interessantes do ponto de vista do amadurecimento pela individuação, na interpretação junguiana e alquímica, por exemplo. Resgatar o sensível dessa educação de escuta, pensamento livre e da narrativa traz a voz e os sonhos de cada singualidade em uma Aula, e nos vincula a uma tradução geofilosófica de nossa relação com a Matéria ${ }^{9}$.

A maioria dos sonhos de mulheres analisados por Signell (1998, p. 26), por exemplo, não se tratava de repetição dos papéis de mãe e de esposa, mas sim em compensatórios quadros referencias quanto a realizações pessoais e relações de infância. A pesquisadora notou que os sonhos com a mãe, isto é, pela similaridade, continuavam o feminino de forma mais clara do que sonhos com o pai, ou seja, pelo contraste. Para esta junguiana, a interpretação dos sonhos não é uma chave pronta que decifra um enigma, mas é um conhecimento traçado pelas sonhadoras ao longo de sua vida, pela experiência entre os seus sonhos, pela aprendizagem de cultivo à imaginação, e pela confiança em si:

Examinar um sonho é como contemplar um poema, uma imagem preciosa, uma pintura expressionista ou surrealista. Você deve olhar para ela a sua própria maneira, deixar que ele a toque, estar atenta para o que se agita mais em você. Eu descobri que, quanto mais trabalhava com estes sonhos [mais de 400 sonhos de mulheres], quanto mais voltava a eles, mais eu conseguia discernir. (SIGNELL, 1998, p. 32)

Na selva onírica, a expansão do pensamento é multidirecional, um sonho segue o outro, nosso radar corporal colhe sonhos alheios. Elaborar sonhos é fazer-se multiplicidades em uma existência transindividual. Um mesmo tema estará costurado entre inúmeros enredos oníricos, uma invenção espreita, pois, nosso sonhar acordado, quando da elaboração secundária (contar um sonho, contar uma Aula, contar um conto).

O desgarramento do ser humano com o sagrado, com a ancestralidade e com o sonho, assumiu também o abandono, de um modo geral, ao valor da poesia: "ao longo dos séculos", nos diz o poeta mexicano Octavio Paz (2015), "Estados e Igrejas confiscaram para seus fins a voz poética". Apesar disso, a poesia manteve seu paradoxo, que é conflito interno de "transmutação do tempo histórico em arquétipo e encarnação desse arquétipo em um agora determinado e histórico [...] afirmação daquilo mesmo que nega: o tempo e a sucessão" (PAZ, 2015, p. 55-56). O sonho, nessa dimensão, também permanece nessa conexão com o tempo em devir, mesclando-se à própria sequência dos fatos da vida, assemelhando-se, assim, à operação poética, porque nunca sonho e poesia encerraram-se no tempo histórico, mas alimentaram-no e dele se nutriram para criar um agora

\footnotetext{
${ }^{9}$ Matéria, pela Filosofia da Diferença, é tudo o que existe em extensão no plano estratigráfico do caosmos, um plano extenso formado pelo conjunto de imagens que temos do mundo. O princípio da matéria é distensão cuja força intrínseca, prolonga-se no espaço: “A matéria não tem representação, tudo o que se obtém dos corpos materiais são sensações, vibrações intensas provocadas pelas substâncias incorporais implicadas na matéria" (ZORDAN, 2019, p. 38).
} 
irrepetível. Nessa perspectiva crítica, trabalhamos a Matéria Sonho para tensionar suas inúmeras forças de criação, bem como traduzir suas potências a-traduzir em ressonâncias poéticas e auleiras, signos que alteram a forma de corpos na vigília.

Quanto à multiplicidade de outras culturas e suas relações com os sonhos, é evidente o quanto desconhecemos e o quanto disso desapareceu ou aculturou-se. Os sincretismos que se manifestam em diversas religiões, por exemplo, são as reminiscências manifestas numa dada cultura desse riquíssimo mundo onírico. Agora há o poeta, ser que respira atemporalmente noutros mundos e, quando sonha, assume essa reponsabilidade de recriação filosófica de existências. Ao brincar com os mitemas que recolhe ou inventa, o poeta os transcria em poemas que convidam uma plateia imaginária à uma vida embriagada pela sensibilidade. Talvez a sutileza, em suas infinitas possibilidades de sentimentos, cante-nos sonhos em sincronia com um ato de criação, no qual, pelas vibrações microscópicas desse continuum onirofílico, o corpo redescobre ciclicamente a alegria de interpretar-se e de traduzir-se pelas suas infinitas potências de vida, na vontade de poesia.

Também há uma estranheza generalizada em relação às manifestações oníricas que não se encaixam ou que não se submetem à teoria psicanalítica, já que esta, grosso modo, interpreta muitos sonhos como manifestação da libido reprimida socialmente. Nessa linha de pensamento, o indivíduo é levado a crer que pode curar suas neuroses ou recalques ${ }^{10}$ somente com a ajuda da interpretação de seus sonhos por um terapeuta.

Nessa perspectiva mais tradicional, a interpretação dos sonhos pode estar decalcada pelas imposições da própria análise. Com Freud, segundo Bastide (2016), o sonho recebeu uma estruturação lógica que se constrói e que se censura. Freud (1966, p. 72) admite, no entanto, os sonhos com caráter de realização de desejos: os não-reprimidos, neles o desejo está claro; os reprimidos, o desejo está disfarçado; e os que representam um desejo reprimido, sem disfarces ou insuficientemente disfarçados, quase sempre interrompidos pela sensação de angústia. O sonho não depende mais de uma conexão do indivíduo ao coletivo ancestral, mas sim é cativo de chaves a ser decifradas pelo terapeuta, como um intérprete de rébus ${ }^{11}$. Para Bastide (2016), a psicanálise é melhor aplicável em grupos menores com limites bem estabelecidos, grupos fortemente restritos a imposições morais e religiosas, como na família tradicional: pai, mãe, filhos. De um modo geral, na psicanálise freudiana tem-se a moral coletiva agindo sobre o sonho individual. Acontece que a função social dos sonhos está muito além do núcleo familiar, mesmo os sonhos sexuais podem ser interpretados numa reflexão salutar dos papéis sociais, como acima problematizado. Ou seja, trata-se de uma revelação ética do sujeito em suas relações de vida, e não de culpabilização.

\footnotetext{
10 Do ponto de vista psicanalítico, não havendo uma "resposta" para o sonho, a maioria das pessoas, segundo Petry (2002, p. 59) tende a recalcá-lo, "vivendo na realização do esquecimento dele, sem poder resgatá-lo como algo que é seu". Esse conceito freudiano (esquecimento do sonho) do recalque "mostra algo da memória do sujeito" que, por não lembrar desse algo, cataloga-o num rol "daquelas coisas que não pode saber ou lembrar, ou seja, não-cessa-de-não-se-inscrever."

${ }^{11}$ Uma obra de René Magritte (1898 -1967), para pensar o rébus de outra maneira, problematizando sonho e linguagem, é a série de pinturas A chave dos sonhos (óleo sobre tela, 1927, disponível em: <https://www.pinakothek.de/kunst/rene-magritte/der-schluessel-der-traeume-0 >. Acesso em 20. jul. 2019). Nela, o artista dispôs imagens e palavras no formato rébus, trazendo inquietantes percepções sobre conceito e objeto. Também aqui poderíamos falar sobre os trocadilhos do sonho.
} 
Sonhar é gerar signos para um aprendizado. Mas educar-se também implica o atento respeito a cada singularidade para não generalizar o que se apreende, mas diferir perspectivas de mundos. Por exemplo, Bastide (2006), em seus estudos acerca da função social do sonho em populações negras, considerando o mito da Negritude, ou seja, a alteridade gerada pelo contato de indivíduos da cultura negra com a cultura dos brancos, demonstrou que a libido ou a constelação familiar (elementos da psicanálise) não poderiam ser usados por um analista que estivesse explicando tais sonhos na cultura de afrodescendentes. Na perspectiva da educação contemporânea, os estudos do sonho a partir de diversas culturas são potências que abrem espaços a pensar pela decolonização acadêmica: contar um sonho sobre aquilo que não foi falado. As narrativas de sonhos podem trazer imagens estereotipadas dos pontos de vista mais diversos, ou seja, independentemente dos valores culturais, temos corpos na academia que internalizaram o patriarcado supremacista branco, por exemplo. Podemos perguntar com Hooks (2019, p. 36): "a partir de qual perspectiva política nós sonhamos, olhamos, criamos e agimos?"

A função social do sonho é também um tipo de testemunho da microhistória, e podemos inverter nossa perspectiva: deparamo-nos com nossos sonhos em uma realidade sem sentido. Por exemplo, o regime totalitário nazista esteve impregnado racionalmente em trezentos sonhos analisados por Beradt (2017). O sonho do senhor S., em que é moralmente despedaçado, o obriga a incorporar uma alienação da realidade que parece prepará-lo ao regime totalitarista que se instalava. A autora percebeu que esses sonhos eram uma espécie de testemunho do mecanismo do regime que afetava e motivava cada pessoa a fazer parte dele e a obedecê-lo nas ações cotidianas. Pensando com Beradt (2017), temos que o trabalho do sonho, em comparação ao da escrita consciente, escreve no corpo amplificações das percepções sentidas interna e externamente pelo sujeito, e a ele sinaliza suas interpretações e traduções, anúncios sensíveis e forças em tensão capazes de potenciar modelizações de um porvir. Um conjunto de sonhos são uma fonte de pesquisa social pelas camadas de eventos que nenhum diário ou anotação documental abarcaria. Ainda, determinados sentimentos, como o terror, e outras reações e emoções não seriam relatados senão em sonhos, que agrupam todas as dimensões temporais, mesmo na aparente atemporalidade.

Koselleck (2017, p. 169-170) aponta três níveis de abordagens teóricas aos sonhos: biográficos (reveladores da individualidade), transpessoais (relacionando-se em revezamentos sociais e políticos), simbólicos (numa linguagem que se faz valer ao longo do tempo). Pode-se isolar um desses níveis para estudos, sem desconsiderar a intercambialidade, posto que um ofusca o outro, e que a análise penderá a um ou a outro nível, conforme a perspectiva adotada. Por exemplo, para preservar as vivências políticas, Beradt (2017) não considerou sonhos eróticos delimitados à biografia particular. Os sonhos mostraram uma espantosa nitidez política dessas camadas burguesas "que se mantiveram fora do partido e de sua organização" (KOSELLECK, 2017, p. 173). As forças propulsoras secretas, e a obrigação de se adaptar a uma realidade nonsense reveladas nesses sonhos levam-nos a problematizar as possíveis interpretações, o quanto os conflitos políticos foram travados no interior dessas pessoas, e como elas tentaram resolvê-los.

Entendemos, pela Educação da Diferença, que é necessário resgatar essa vida de sonhos, de devires do desejo, de sono que conecta o indivíduo a um cosmos social e ancestral, indivíduo cujas 
pequenas percepções oníricas se manifestam na vigília, imperceptivelmente. Independentemente de crenças ou de imposições, os sonhos resistem minoritariamente nos corpos. Há de se dar a devida importância aos momentos em que os sonhos acontecem, como nos aconselha Artemidoro, embora não conjugamos com a ideia de busca de uma verdade e tampouco aspiramos a reter os apetites. Mas, para sonhar dormindo,

[...] a noite em nada difere do dia, nem o crepúsculo vesperal do crepúsculo da aurora, com a condição, é claro, de ter adormecido depois de ter-se alimentado com moderação, pois as refeições imoderadas não permitem que se veja a verdade nem mesmo nos sonhos que se produzem ao alvorecer. (ARTEMIDORO, 2009, p. 31)

Considerando que o sonho é um tipo de obra autoral de uma singularidade, e que no umbigo do sonho (parte estranha do sonho, pedaço a-traduzir do desejo) temos o labor onírico e inconsciente, podemos traçar um paralelo com a escrita, pois nela o autor é o princípio do trabalho de seu pensamento numa unidade, "pelo que todas as diferenças são reduzidas pelos princípios da evolução, da maturação ou da influência" (FOUCAULT, 2002, p. 53). A escrita é um jogo de signos que elabora uma outra potência de pensamento. Nesse jogo, as regras são ordenadas pelo escritor: por exemplo, ao elaborar a escrita de um sonho, é provocado um experenciar-se em desdobramentos internos que são extravasados (externados) pela tradução a um outro (outra voz). Jogo que corre até a eliminação do sujeito que escreve, até que o desejo seja quase palavreado. Uma sonhografia acontece na medida em que se deixam espaços a-traduzir, onde há deslocamentos de linguagem, inversões de sentido, brechas que respiram devires autopoiéticos a um outro.

$\mathrm{Na}$ aplicação prática, por exemplo, de instalação de um estudo de conteúdo onírico em determinado grupo, é interessante coletar dados sociais, já que os sonhos abarcam memórias individuais ${ }^{12}$ mas também contém arquétipos ancestrais e recortes da dinâmica dos quadros sociais que o sonhador está vivendo. Sua construção e tradução dependerá da maneira como os indivíduos agem e sentem o seu meio social. Por exemplo, Bastide (2016, p. 37) aponta que, além do nome, idade, antecedentes psicopáticos do sonhador, é necessário indicar a profissão, a cultura e o meio social13. Já em Artemidoro, segundo Parker (1985, p 15), é bom considerar, para a prática onirocrítica, as variáveis: nome do sonhador, ocupação, condições nas quais o sonho ocorreu, se o sonho foi natural, se foi legítimo ou se foi costumeiro.

Esses apontamentos nos interessam a deslocamentos por um pensamento de sonhos em educação, ou para a elaboração de exercícios de escrita e sonho via didática artística, pois a função social do poema se agrega à do sonho. Um poema é ato histórico de "expressão de uma sociedade e, simultaneamente [...] condição de sua existência. Sem palavra comum não há poema; sem palavra poética tampouco há sociedade" (PAZ, 2015, p. 52), portanto também a poesia se constitui produto social e, como o sonho, é condição prévia à existência de uma sociedade.

\footnotetext{
12 "O Sonho é um movimento ou uma modelagem polimorfa da alma que significa o bem ou o mal que virá com os acontecimentos futuros. [...]" (ARTEMIDORO, 2009, p. 23).

${ }^{13} \mathrm{Na}$ tipologia que Bastide (2016) sugere-nos, há os sonhos de vingança, os sonhos de invasão, os sexuais, os de continuação de trabalho (matemático, literário): “é essa tipologia que deve ser função da vida social” (BASTIDE, 2016, p. 34).
} 
Sonhografias poéticas são parte dessa tradução que é educação social, reafirmando e reinventando uma cultura pela docência criadora e apaixonada, é o professor-tradutor o portador da vontade de potência que transporta, transpõe e transfere criadoramente seu sonho no currículo e na didática, ao mesmo tempo em que condensa um sujeito social coletivo, intrinsecamente dotado de vida afirmativa.

\section{CONCLUSÃO}

Na construção de um aprendizado pela Diferença, o tipo de cânone individual na docênciapesquisa (mito-individual) pode ser traçado a partir dos estudos de sonho e de poseia curricular: cada sonhador/docente/aluno elege de sua matéria, a partir do arquivo da educação, autores(as) para criar o coletivo sonho/aula, para criar uma alfabetização via labor de sonho literário-mítico. Há ainda de se considerar, para que se eleve a definição estrutural do sonho dada pela psicanálise (individual da personalidade profunda) que, conforme Bastide (2016, p. 60), "os sonhos se inscrevem num determinado quadro de certa civilização e de certo sistema social".

Os sonhos trocam, acrescentam, retiram, reescrevem mitos sociais, e não apenas agregam-se aos arquétipos estanques ancestrais. Cada indivíduo, ao longo de sua vida sonhada cria seu mito, sonhando reescreve-se. Isso é uma criação movente, que troca e renova tanto as percepções individuais como as relações entre os grupos sociais durante a práxis da vigília. Nessa continuidade da relação entre o noturno e diurno, comprovada por diversos estudos etnológicos, Bastide (2006, p. 130131) acrescenta que: "sendo o sonho a linguagem do desejo, e o sofrimento o que é provocado por sua não-satisfação, o estado de vigília há de ser sempre a mimese do estado noturno" e que na vigília pode-se realizar, parcialmente ou simbolicamente, nossos sonhos. Como ficção humana, em seu aspecto formal, os sonhos não nos apresentam fatos, mas nos movem em sua tradução de uma realidade da qual provêm. Além disso, os sonhos produzem uma qualidade poética, que nos desafia a constatações que nunca seriam percebidas noutras fontes, pois trazem à tona, em suas imagens, ações, citações, palavras, jogos, uma dimensão obscura da estrutura da realidade.

Propomos esse início de tensionamento à educação contemporânea, via a Filosofia da Diferença, a fim de perspectivar a função social e poética do sonho como análises críticas e não moralistas. Pensar sonhos didáticos como deslocamentos transindividuais na docência-pesquisa, com suas problematizações entrelaçadas aos diversos temas da vida que escreve-pesquisa-traduz Aulas em seus discursos da subjetividade, no direito à poética e à fantasia ou nos testemunhos das relações de classe e de gênero que ressemantizam uma história em uma atualidade.

\section{REFERÊNCIAS}

1. ARTEMIDORUS, Daldianus. Livro I - Considerações gerais. In: ARTEMIDORUS, Daldianus. Sobre a interpretação dos sonhos (Oneirocritica). Trad. Eliana Aguiar. Rio de Janeiro: Jorge Zahar Ed., 2009. p. 21-33. 
2. BASTIDE, Roger. Sociologia do Sonho. In: BASTIDE, Roger. O sagrado selvagem e outros ensaios. Trad. Dorothée de Buchard. São Paulo: Companhia das Letras, 2006. p. 127-145.

3. BASTIDE, Roger. O Sonho. In: BASTIDE, Roger. O sonho, o transe e a loucura. Trad. Carlos Eugênio Marcondes de Moura. São Paulo: Três Estrelas, 2016. p. 25-89.

4. BENJAMIN, Walter. A tarefa do tradutor [1921]. In: BENJAMIN, Walter. Escritos sobre mito e linguagem. Trad. Suzana Kampff Lages e Ernani Chaves. São Paulo: Ed. 34, 2011. p. 101-119.

5. BERADT, Charlotte. Sonhos no Terceiro Reich: a origem da ideia. In: BERADT, Charlotte. Sonhos do Terceiro Reich. Trad. Silvia Bittencourt. São Paulo: Três Estrelas, 2017. p. 29-55.

6. BORGES, Jorge Luis. Livro dos Sonhos. Trad. Cláudio Fornari. $3^{a}$ ed. São Paulo: Difel, 1985.

7. FOUCAULT, Michel. 1954 - Introdução (Binswanger). In: FOUCAULT, Michel. Problematização do sujeito: psicologia, psiquiatria e psicanálise. 2. ed. Rio de Janeiro: Forense Universitária, 2002. p. 71-132.

8. FOUCAULT, Michel. Nietzsche, Freud e Marx. Theatrum Philosoficum. Trad. Jorge Lima Barreto. Ed. Princípio, 1997.

9. FREUD, Sigmund. Los sueños. Trad. Luis López-Ballesteros Y de Torres. Madri: Aliança Editorial. 1966.

10. HOOKS, Bell. Introdução: atitude revolucionária. In: HOOKS, Bell. Olhares Negros: raça e representação. Trad. Stephanie Borges. São Paulo: Elefante, 2019. p. 31-42.

11. JUNG, Carl Gustav. Consideraciones generales sobre la psicología del sueño. In: JUNG, Carl Gustav. Energetica psiquica y esencia del sueño. Trad. Ludovico Rosenthal e Blas Sosa. Buenos Aires: Paidos, 1954. p. 108-163.

12. KOSELLECK, Reinhart. Posfácio In: BERADT, Charlotte. Sonhos do Terceiro Reich. Trad. Silvia Bittencourt. São Paulo: Três Estrelas, 2017. p. 162-182.

13. PARKER, Derek \& Julia. O mundo dos sonhos: um guia ilustrado para lembrar e interpretar os sonhos. Trad. Carmen Fischer. São Paulo: Círculo do Livro, 1985.

14. 15. PAZ, Octavio. A imagem. In: PAZ, Octavio. Signos em Rotação. Trad. Sebastião Uchoa Leite. São Paulo: Perspectiva. 4. ed. 2015. p. 37-50. 
15. PETRY, Luís Carlos. Traumdeutung: cem anos de interatividade - Psicanálise e modelagem 3D na produção de sentidos. In: DA ROSA Jr., Norton Cezar; CORREIA, S. (Org.). A interpretação dos sonhos: Várias Leituras. São Leopoldo/RS: UNISINOS, 2002. p. 57-102.

SIGNELL, Karen A. Entendendo os sonhos. In: SIGNELL, Karen A. A sabedoria dos Sonhos: para desvendar o inconsciente feminino. Trad. Carmen Fischer. São Paulo: Ágora, 1998. p. 35-63.

17. TIRKKONEN, Sanna. Investigating the Existential A Priori by Rethinking Dream Experience. In: TIRKKONEN, Sanna. Experience in Michel Foucault's Philosophy. 2018. 246 f. Tese (Doutorado em Educação) - Practical Philosophy. Faculty of Social Sciences, University of Helsinki, Finlância, $2018 . \quad$ p. 34-40. Dsiponível em: https://helda.helsinki.fi/bitstream/handle/10138/242415/Experien. pdf?sequence=1\&isAllowed=y> . Acesso em: 29. jul. 2019. Martins Fontes, 2011.

19. ZORDAN, Paola. Matérias. In: ZORDAN, Paola. Gaia Educação: arte e filosofia da diferença. Curitiba: Appris, 2019. p. 33-38.

\section{Sandra Mara Corazza}

Doutora em Educação, Professora Titular Permanente no Programa de Pós-Graduação em Educação da Universidade Federal do Rio Grande do Sul, Porto Alegre/RS, Brasil. Pesquisadora de Produtividade do CNPq 1B.

\section{Marina dos Reis}

Mestra em Educação pelo Programa de Pós-Graduação em Educação da Universidade Federal do Rio Grande do Sul, Porto Alegre/RS, Brasil.

\section{Como citar este documento:}

CORAZZA, Sandra Mara; REIS, Marina dos. Sonho e Educação: deslocamentos pela filosofia da diferença. Reflexão e Ação, Santa Cruz do Sul, v. 28, n. 2, jun. 2020. ISSN 1982-9949. Disponível em: $<$ https://online.unisc.br/seer/index.php/reflex/article/view/14013>. Acesso em: doi:https://doi.org/10.17058/rea.v28i2.14013. 